American J. of Engineering and Applied Sciences 1 (2): 110-117, 2008

ISSN 1941-7020

(C) 2008 Science Publications

\title{
Effect of Confinement on the Axial Performance of Fibre Reinforced Polymer Wrapped RC Column
}

\author{
A. Rajasekaran, P.N. Raghunath and K. Suguna \\ Department of Structural Engineering, Annamalai University, \\ Annamalai Nagar-608 002, India
}

\begin{abstract}
The combined effect of internal steel ties and external FRP wrap was investigated using nine reinforced concrete columns with varying thickness of external wrap. The load, deflection and lateral expansions were studied at yield state and ultimate state. The results from the experimental investigations were used for performing a multi-variate linear regression analysis incorporating the contribution of tie spacing as a term. The predictions of the regression equation agreed well with the experimental results and showed sensitive difference in compressive strength for changes in tie spacing.
\end{abstract}

Key words: Fibre reinforced polymer, axial performance, reinforced concrete column

\section{INTRODUCTION}

Reinforced concrete columns require confinement in the lateral direction for enhanced performance against axial loads. These columns were confined with lateral steel ties, either in the form of circular rings or in the form of spirals running from top to bottom of the column. Wrapping with FRP is an additional measure for providing confinement to the reinforced concrete column, which is much more effective than the steel ties. The provision of FRP wrap leads to better resistance to axial loads, increased axial stiffness and higher deformability of the column.

Models are proposed for estimating the stress strain behaviour of FRP confined concrete under varying load transfer and geometric conditions. Loading on concrete core, loading on concrete core as well as FRP confinement and loading the concrete core of section with inner void were considered in the analytical investigation. These models were capable of tracing the entire stress strain behaviour of FRP confined concrete columns. The results of the model were validated by comparing them with experimental data belonging to the MS thesis work of Jurgen Becque and those published by Saaman et al. ${ }^{[2]}$.

Models are proposed for predicting the behaviour of steel tie confined circular columns with normal strength and high strength concrete core. The model was applicable for columns having internal steel reinforcement. The effectiveness of hoop steel confinement was measured using a dimensionless parameter which was related to the amount of transverse reinforcement, the compressive strength of concrete and yield strength of transverse reinforcement. The results predicted by the model agreed well with large number of published results for both concentrically loaded columns and columns subjected to constant axial load and reversed cyclic flexure ${ }^{[5]}$.

Experiments were conducted for investigations to identify the complicating effects produced by variations in geometry and loading eccentricities. Specimens having circular, square and rectangular cross sections were tested with GFRP and CFRP wraps of varying combinations and configurations. Testing was carried out under concentric loading and at $20 \mathrm{~mm}$ eccentricity. A correction factor was suggested to account for the reduction in strength of slender columns. Confinement effectiveness factor was introduced to measure the effect of FRP confinement on the performance of concrete columns. FRP confinement proved to be most effective for circular cross section and least effective for rectangular cross section ${ }^{[8]}$.

Various theoretical models were compared with available literature to assess their suitability for estimating the strength of FRP confined concrete columns. The assessment included non-linear elastic models (proposed by Ottosen, Elwi and Murray, Ahmad and Shah, Ahmad, Shah and Khaloo) and elastoplastic models (proposed by Chen). The nonlinear elastic models were found to be dissatisfactory due to the fact that they did not account for variation in confinement pressure as the axial stress increased. The

Corresponding Author: A. Rajasekaran, Department of Structural Engineering, Annamalai University, Annamalai Nagar-608 002, India 
elasto-plastic model agreed well with experimental $\operatorname{data}^{[3]}$.

Experimental investigations were carried out on twenty seven concrete cylinders of wrapped with GFRP having various fibre orientations to assess the impact of the fibre orientation on the performance of FRP confined concrete cylinders. The cylinders confined with two layers of $45^{\circ}$ wrap and four layers of axial wrap performed very poorly. Specimens with two layers of $0^{\circ}$ fibres had slightly higher strength compared to specimens with one layer of $0^{\circ}$ fibres and second layer of $90^{\circ}$ fibres. Failure of columns was mostly due excessive transverse tensile stress or inplane shear stress in FRP except in the case of $0^{\circ}$ fibres. The study found that fibre orientation and FRP wall thickness had a considerable impact on the stress-strain behaviour, strength, ductility and failure mode of wrapped concrete cylinders ${ }^{[6]}$.

The behaviour of FRP confined reinforced concrete circular columns subjected to concentric loads and eccentric loads were studied. Confinement was provided with three layers of CFRP and three layers of GFRP. Columns tested under $25 \mathrm{~mm}$ eccentricity remained in tact up to failure, while those tested less than $50 \mathrm{~mm}$ eccentricity showed premature failure. The behaviour of GFRP wrapped concrete columns and unwrapped columns remained similar under concentric load and at $25 \mathrm{~mm}$ eccentricity of loading. The externally confined concrete columns underwent large deformations without rupture ${ }^{[4]}$.

The seismic behaviour of high strength concrete columns cast in CFRP stay-in-place formworks with varying corner radii were studied. The core portion was provided with additional internal FRP ties to improve the confinement. The experiments were carried out by loading the column to 30 or $34 \%$ of the axial load capacity and subjecting it to progressively incremental dirft capacities in full cycle reversed loading. The columns showed no difference upto $2 \%$ drift ratio. At $3 \%$ drift, the CFRP showed distress by forming patches of discolouring at the plastic hinge portions at top and bottom of the column. The CFRP ruptured at $4 \% \mathrm{drift}$ ratio. The failure of columns was signified by the rupture of CFRP encasement near the corner of the cross section. The maximum drift ratio reached was $11 \%$, indicating highly flexural behaviour of the column. Corner radius played a significant role in the onset of failure. While columns having corner radius ratio of 1/6 showed initial distress at $6 \%$ drift, those with corner radius ratio of $1 / 34$ showed initial distress at $2 \% \mathrm{drift}^{[9]}$.

The present investigation was carried out on nine reinforced concrete columns, with lateral at three different tie spacings. Three columns were tested without any wrap, three more with $3 \mathrm{~mm}$ thick GFRP wrap and another three with $5 \mathrm{~mm}$ thick GFRP wrap. Regression analysis was also carried out and equations proposed for estimating the load carrying capacity and ultimate strain capacity.

\section{RESEARCH SIGNIFICANCE}

The investigation revealed the effectiveness of FRP on reinforced concrete columns which already have lateral ties. Most of the investigations on FRP confined concrete were based on the results obtained from unreinforced concrete cylinders, but the present investigation considered reinforced concrete columns, which would be representative of the real world situation where FRP strengthening is adopted on reinforced concrete columns rather than plain concrete.

The regression equations proposed from the results of the investigation are suitable for estimating the compressive strength of reinforced concrete columns with spacing of internal ties as a parameter.

\section{EXPERIMENTAL INVESTIGATION}

The experimental investigations were carried out on nine reinforced concrete columns having $150 \mathrm{~mm}$ diameter, $1200 \mathrm{~mm}$ height, six rods of $8 \mathrm{~mm}$ diameter for longitudinal reinforcement and $6 \mathrm{~mm}$ diameter mild steel ties spaced at $115 \mathrm{~mm}, 165 \mathrm{~mm}$ and $215 \mathrm{~mm}$ for internal lateral confinement.

Out of the nine columns, three reference columns were tested without any wrapping. GFRP wrapping was provided at $3 \mathrm{~mm}$ thickness and $5 \mathrm{~mm}$ thickness for remaining columns. The designations of experimental specimens and their details are presented in Table 1.

Material properties: The concrete used for casting the specimens was designed for target strength of $20 \mathrm{MPa}$ with mix ratio of 1:1.54:3:0.5 (cement: fine aggregate: coarse aggregate: water). The characteristic compressive strength achieved was 23.64 MPa. The

\begin{tabular}{|c|c|c|c|c|c|}
\hline $\begin{array}{l}\text { S1. } \\
\text { No. }\end{array}$ & $\begin{array}{l}\text { Specimen } \\
\text { Designation }\end{array}$ & $\begin{array}{l}\text { Diameter } \\
(\mathrm{mm})\end{array}$ & $\begin{array}{l}\text { Tie spacing } \\
(\mathrm{mm})\end{array}$ & $\begin{array}{l}\text { Type of } \\
\text { GFRP }\end{array}$ & $\begin{array}{l}\text { Thickness of } \\
\text { GFRP }(\mathrm{mm})\end{array}$ \\
\hline 1. & R0T115 & 150 & 115 & - & 0 \\
\hline 2. & R0T165 & 150 & 165 & - & 0 \\
\hline 3. & R0T215 & 150 & 215 & - & 0 \\
\hline 4. & U3T115 & 150 & 115 & UDC & 3 \\
\hline 5. & U3T165 & 150 & 165 & UDC & 3 \\
\hline 6. & U3T215 & 150 & 215 & UDC & 3 \\
\hline 7. & U5T115 & 150 & 115 & UDC & 5 \\
\hline 8. & U5T165 & 150 & 165 & UDC & 5 \\
\hline 9. & U5T215 & 150 & 215 & UDC & 5 \\
\hline
\end{tabular}


Table 2: Properties of GFRP

\begin{tabular}{llllll}
\hline S1. No. & Type of Fibre in GFRP & Thickness $(\mathrm{mm})$ & Tensile Strength (MPa) & Ultimate Elongation (\%) & Elasticity Modulus (MPa) \\
\hline 1. & Uni-Directional Cloth & 3 & 446.90 & 3.02 & 13965.63 \\
2. & Uni-Directional Cloth & 5 & 451.50 & 2.60 & 17365.38 \\
\hline
\end{tabular}

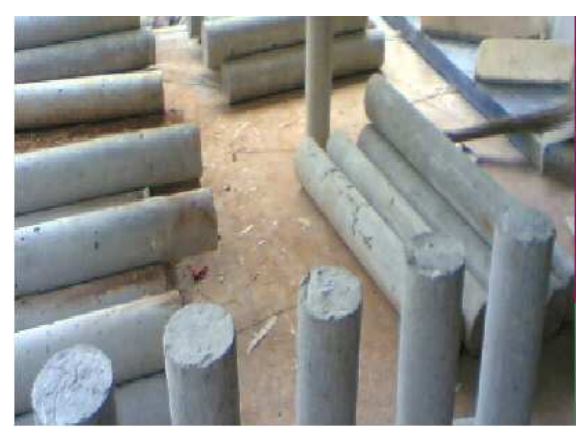

Fig. 1a: Specimens for wrapping

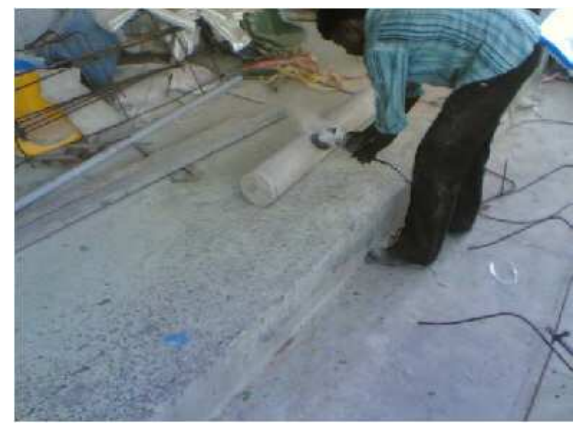

Fig. 1b: Cleaning the specimens

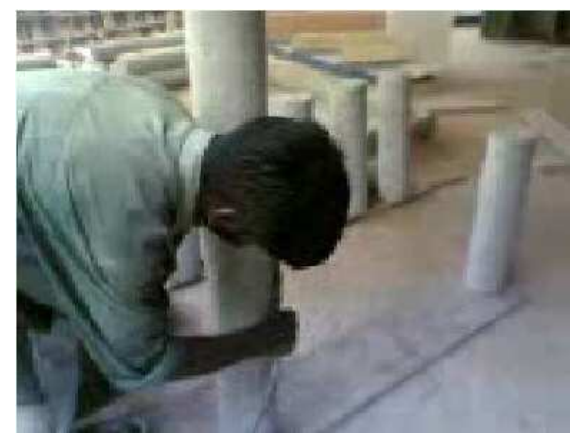

Fig. 1c: Cleaning with compressed air

steel used for longitudinal reinforcement was ribbed tar steel with yield strength of $415 \mathrm{MPa}$, while that used for lateral ties was mild steel with yield strength of 250 MPa. The properties of GFRP used for the investigation are presented in Table 2. The mat for GFRP, called Uni-Directional Cloth, had glass fibres oriented at $0^{\circ}$ to the direction of FRP fabric (or perpendicular to the axis of the column),

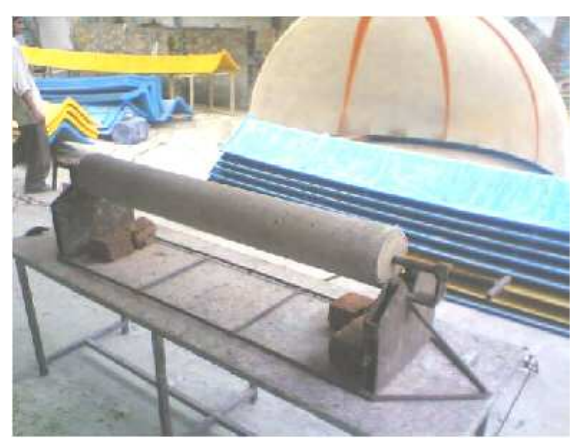

Fig. 1d: Column ready for wrapping

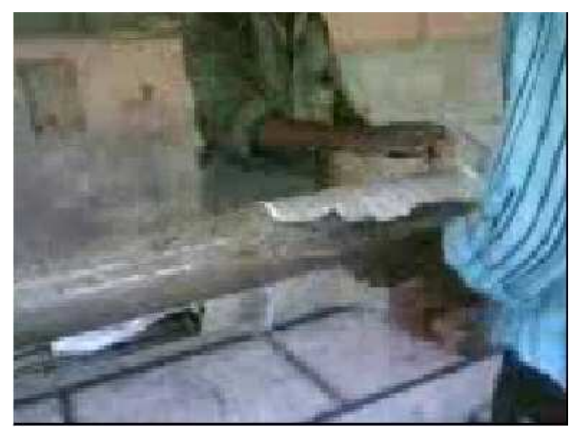

Fig. 1e: Wrapping of specimen

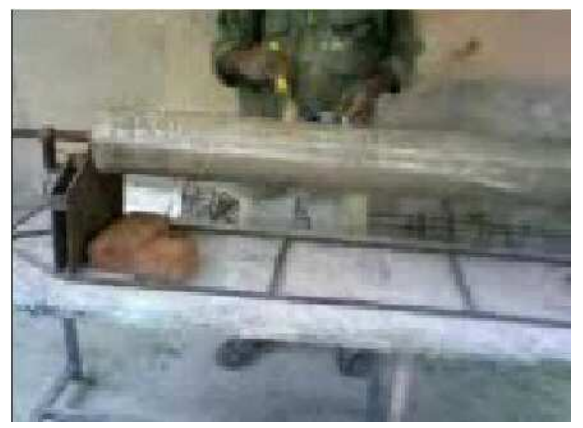

Fig. 1f: Wrapping of column nearly complete

Wrapping the columns: The column were cast in asbestos cement pipe moulds, cured and prepared for wrapping by rubbing and blowing the surface to remove loose materials. The process of wrapping the columns is shown in Fig. 1a-f.

Testing the columns: The columns were tested on a loading frame having $2000 \mathrm{kN}$ capacity. The columns 


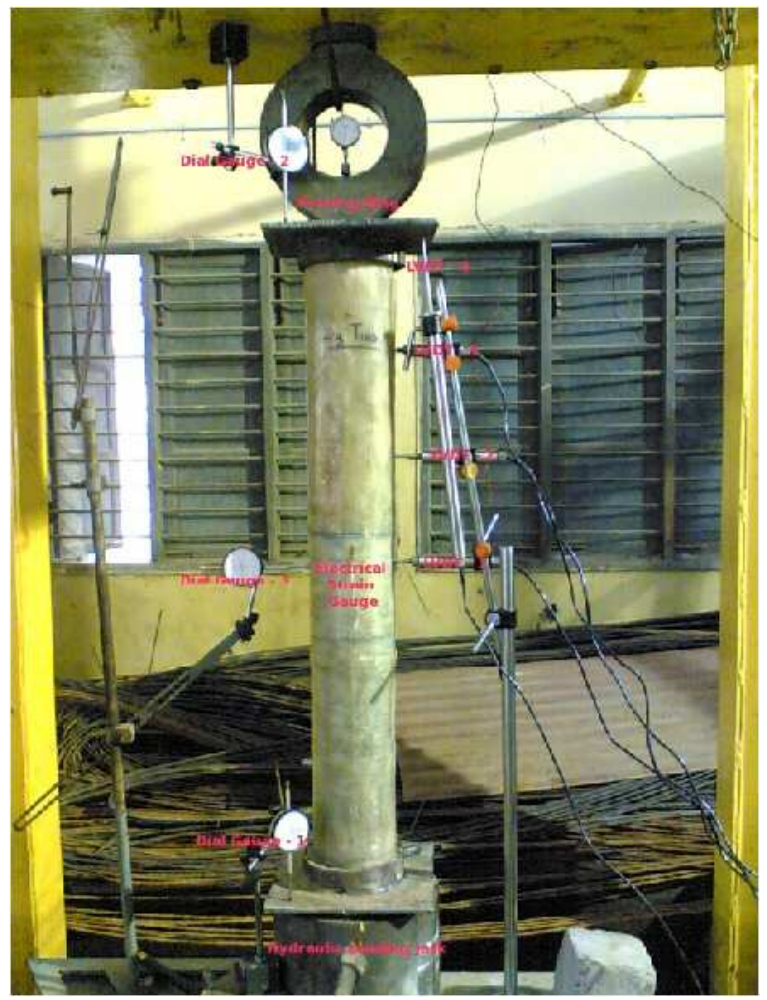

Fig. 2: Instrumentation details for the column

were instrumented using deflectometers at top and bottom for measuring the axial deformation, electrical strain gauges to measure the axial and lateral strains in FRP wrap and Linear Variable Dielectric Transducers for measuring the lateral deformation. Typical specimen mounted for testing is shown in Fig. 2. The axial compressive load was applied monotonically in steps on $500 \mathrm{~N}$ and the readings from various instruments noted for each load increment. Most of the GFRP wrapped columns exhibited high levels of deformability and post yield deflection capacity.

\section{TEST RESULTS AND DISCUSSION}

The stress-strain behaviours for the experimental columns are shown in Fig. 3. The results pertaining to yield level and ultimate level are presented in Table 3 and 4 . The results pertaining to the deflection ductility and energy ductility are presented in Table 5.

The stress-strain curves comprised of two distinct limbs, one linear limb before failure of the core concrete (the yield point of the GFRP composite strengthened column) and second non-linear limb where the GFRP is active. The behaviour of GFRP wrapped columns remained similar to that of

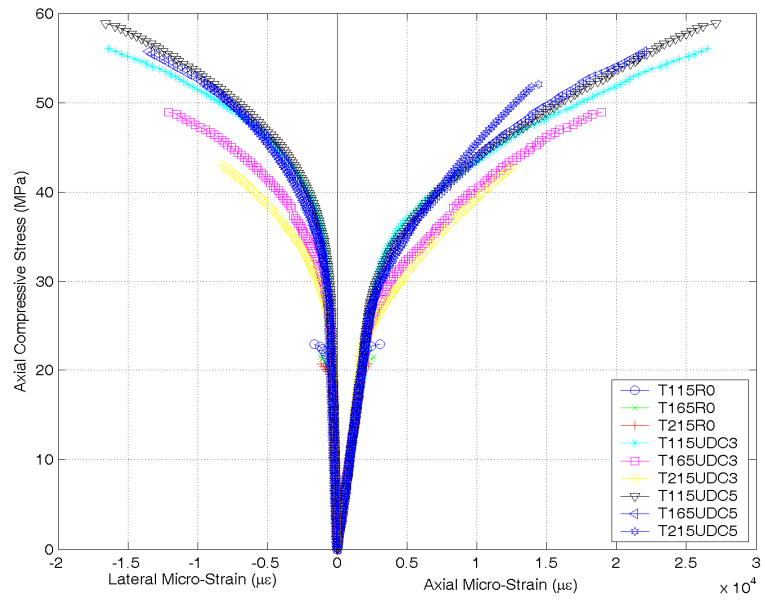

Fig. 3: Stress-strain behaviour of columns with UDCGFRP wrapping

corresponding unwrapped column up to the yield point, where the core concrete fails due to compressive forces. Beyond this point, the GFRP wrap became active, since the concrete core was ready to expand more in the lateral direction.

The expansion of the concrete core in the lateral direction made the GFRP more and more active in resisting the axial compressive forces by building a force called the lateral confining pressure. When the strain in GFRP reached sufficiently high values (but less than the ultimate strain determined from tensile coupon tests, due to the presence of surface irregularities, random packets of higher stress concentration, non-uniformity in the properties of GFRP wrap or inadequate overlap), the wrap material failed, thus permitting the column to fail. Figs. 4a-h show the comparative performances related to yield point, ultimate point and ductility values.

The influence of wrap thickness was calculated taking the results for unwrapped columns as reference, keeping the slenderness ratio constant. The influence of slenderness ratio was calculated with reference to the columns having slenderness ratio of 32, keeping the wrap thickness constant.

Effect of wrap thickness on yield level performance: The maximum increase in yield load at $60.56 \%$ was observed for 3 thick UDCGFRP wrapped column having tie spacing of $115 \mathrm{~mm}$. The yield deflection values for reinforced concrete columns wrapped with 5 $\mathrm{mm}$ thick UDCGFRP showed $38.89 \%$ increase for 215 $\mathrm{mm}$ tie spacing, $60.61 \%$ for $165 \mathrm{~mm}$ tie spacing and $56.40 \%$ increase for $115 \mathrm{~mm}$ tie spacing. A maximum increase of $119.87 \%$ in lateral deflection was observed for the case of T115UDC3 column. 
Am. J. Engg. \& Applied Sci., 1 (2): 110-117, 2008

Table 3: Results at yield level

\begin{tabular}{llllllll} 
S1. No. & Designation & $\begin{array}{l}\text { Yield } \\
\text { load }(\mathrm{kN})\end{array}$ & $\begin{array}{l}\text { Axial yield } \\
\text { deflection }(\mathrm{mm})\end{array}$ & $\begin{array}{l}\text { Lateral Yield } \\
\text { deflection }(\mathrm{mm})\end{array}$ & $\begin{array}{l}\text { Yield } \\
\text { stress (MPa) }\end{array}$ & $\begin{array}{l}\text { Axial } \\
\text { micro-strain }\end{array}$ & $\begin{array}{l}\text { Lateral } \\
\text { micro-strain }\end{array}$ \\
\hline 1 & T115R0 & 355 & 2.11 & 0.05 & 20.09 & 1758.33 & 317 \\
2 & T165R0 & 340 & 1.98 & 0.04 & 19.24 & 1650 & 281 \\
3 & T215R0 & 335 & 1.98 & 0.04 & 18.96 & 1650 & 281 \\
4 & T115UDC3 & 570 & 3.8 & 0.1 & 32.26 & 3166.67 & 697 \\
5 & T165UDC3 & 445 & 2.81 & 0.08 & 25.18 & 2341.67 & 515 \\
6 & T215UDC3 & 400 & 2.13 & 0.06 & 22.64 & 1775 & 373 \\
7 & T115UDC5 & 525 & 3.3 & 0.08 & 29.71 & 2750 & 550 \\
8 & T165UDC5 & 495 & 3.18 & 0.09 & 28.01 & 2650 & 610 \\
9 & T215UDC5 & 475 & 2.75 & 0.08 & 26.88 & 2291.67 & 504 \\
\hline
\end{tabular}

Table 4: Results at ultimate level

\begin{tabular}{llllllll}
\hline S1. No. & Designation & Load $(\mathrm{kN})$ & $\begin{array}{l}\text { Axial } \\
\text { deflection }(\mathrm{mm})\end{array}$ & $\begin{array}{l}\text { Lateral } \\
\text { deflection }(\mathrm{mm})\end{array}$ & $\begin{array}{l}\text { Yield } \\
\text { stress }(\mathrm{MPa})\end{array}$ & $\begin{array}{l}\text { Axial } \\
\text { micro-strain }\end{array}$ & $\begin{array}{l}\text { Lateral } \\
\text { micro-strain }\end{array}$ \\
\hline 1 & T115R0 & 405 & 3.70 & 0.23 & 22.92 & 3083.33 & 1536.00 \\
2 & T165R0 & 380 & 3.12 & 0.20 & 21.50 & 2600.00 & 1345.00 \\
3 & T215R0 & 365 & 2.64 & 0.18 & 20.65 & 2200.00 & 1189.00 \\
4 & T115UDC3 & 990 & 31.84 & 2.47 & 56.02 & 26533.33 & 16492.00 \\
5 & T165UDC3 & 865 & 22.75 & 1.85 & 48.95 & 18958.33 & 12344.00 \\
6 & T215UDC3 & 760 & 15.25 & 1.24 & 43.01 & 12708.33 & 8265.00 \\
7 & T115UDC5 & 1040 & 32.54 & 2.52 & 58.85 & 27116.67 & 16812.00 \\
8 & T165UDC5 & 985 & 26.37 & 2.04 & 55.74 & 21975.00 & 13630.00 \\
9 & T215UDC5 & 920 & 17.32 & 1.39 & 52.06 & 14433.33 & 9248.00 \\
\hline
\end{tabular}

Table 5: Ductility values

\begin{tabular}{llllll}
\hline Sl. No. & Designation & Deflection Ductility & Energy Ductility & Deflection Ductility Ratio & Energy Ductility Ratio \\
\hline 1 & T115R0 & 1.75 & 2.72 & 1 & 1.00 \\
2 & T165R0 & 1.58 & 2.23 & 1 & 1.00 \\
3 & T215R0 & 1.33 & 1.69 & 1 & 1.00 \\
10 & T115UDC3 & 8.38 & 21.18 & 4.78 & 7.78 \\
11 & T165UDC3 & 8.1 & 22.32 & 5.14 & 10.03 \\
12 & T215UDC3 & 7.16 & 19.85 & 5.37 & 10.76 \\
13 & T115UDC5 & 9.86 & 28.23 & 5.62 & 10.77 \\
14 & T165UDC5 & 8.29 & 23.97 & 5.26 & 10.03 \\
15 & T215UDC5 & 6.3 & 16.94 & 4.72 & \\
\hline
\end{tabular}

Effect of wrap thickness on yield level performance: The compressive load carrying capacity increased by a maximum of $152.05,159.21$ and $156.79 \%$ for the columns T115UDC5, T165UDC5 and T215UDC5. In

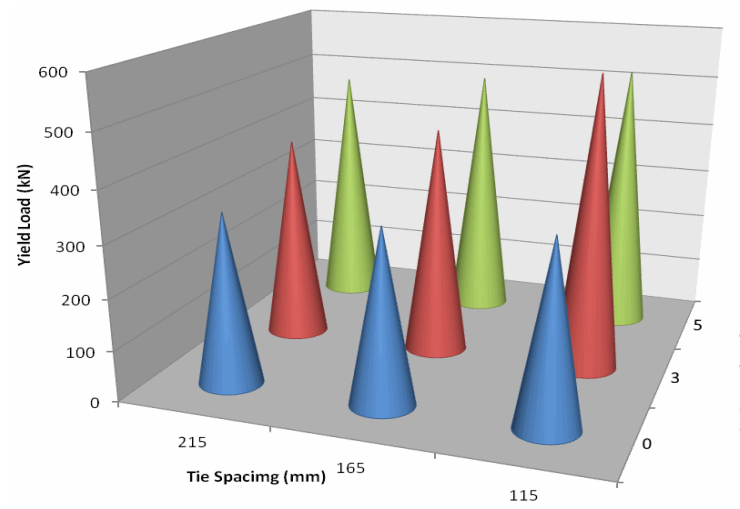

Fig. 4a: Yield load all thickness ranges, UDCGFRP provided the maximum increase in load carrying capacity. The UDCGFRP wrapped columns showed increase in ultimate deflection by up to $779.46 \%$, which was

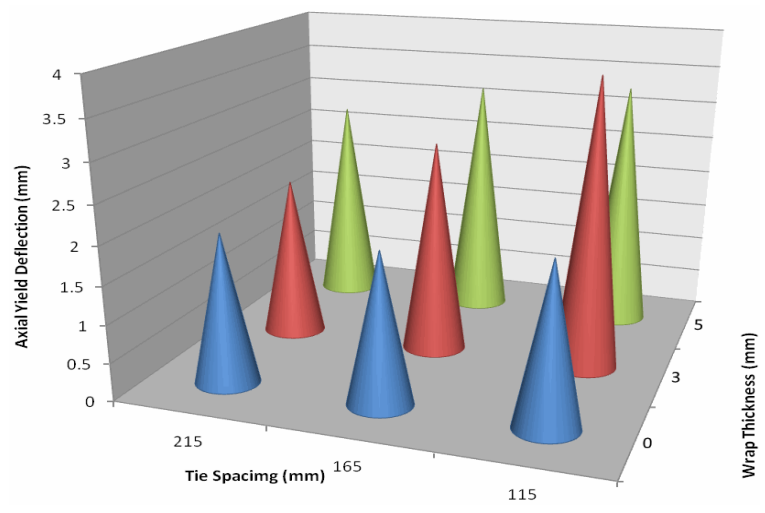

Fig. 4.b Yield Deflection 


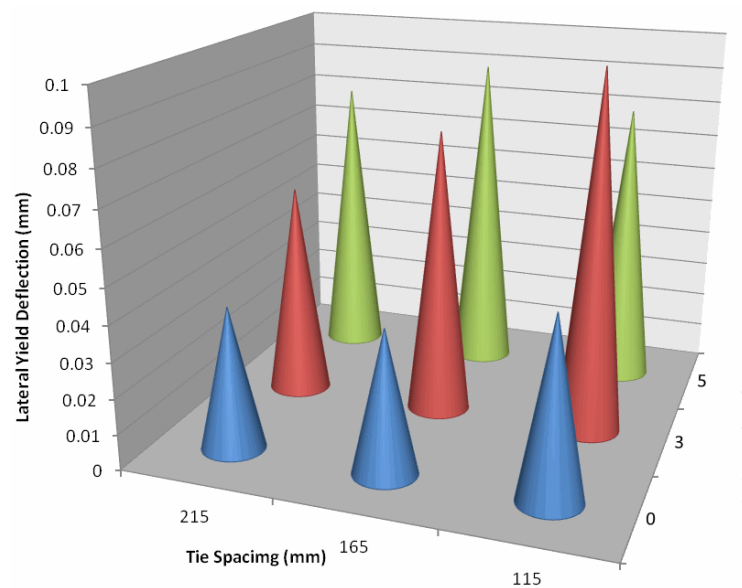

Fig. 4c: Lateral Yield Deflection

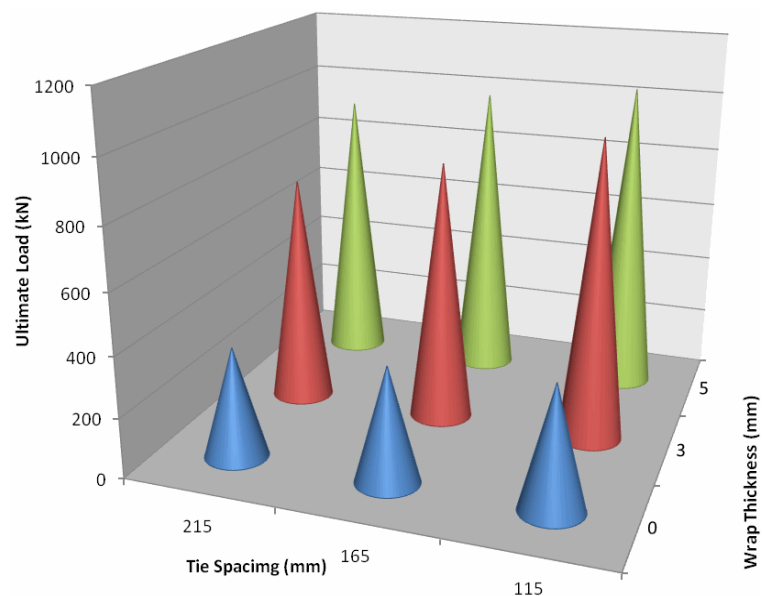

Fig. 4.d Ultimate Load

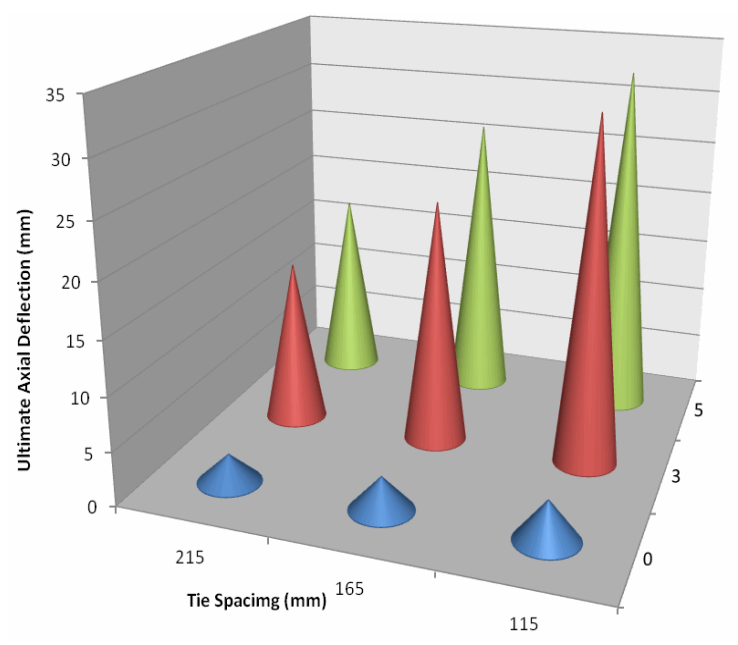

Fig. 4e: Ultimate deflection

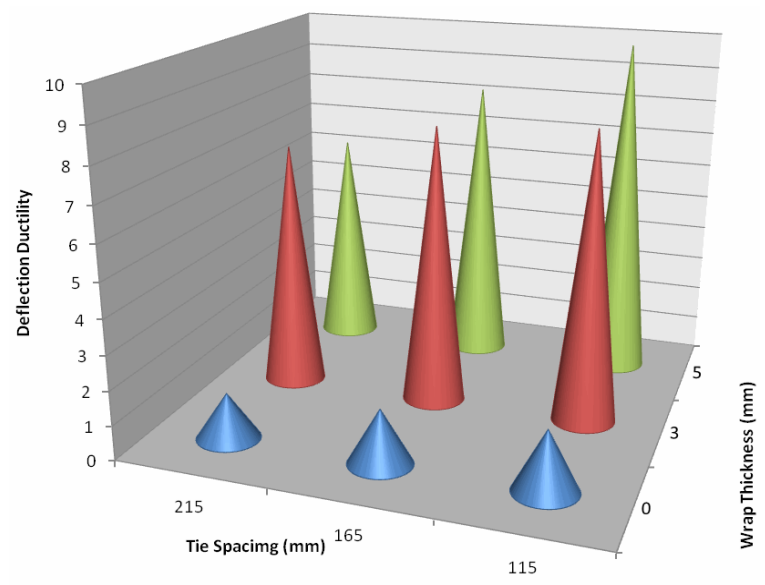

Fig. 4g: Deflection ductility

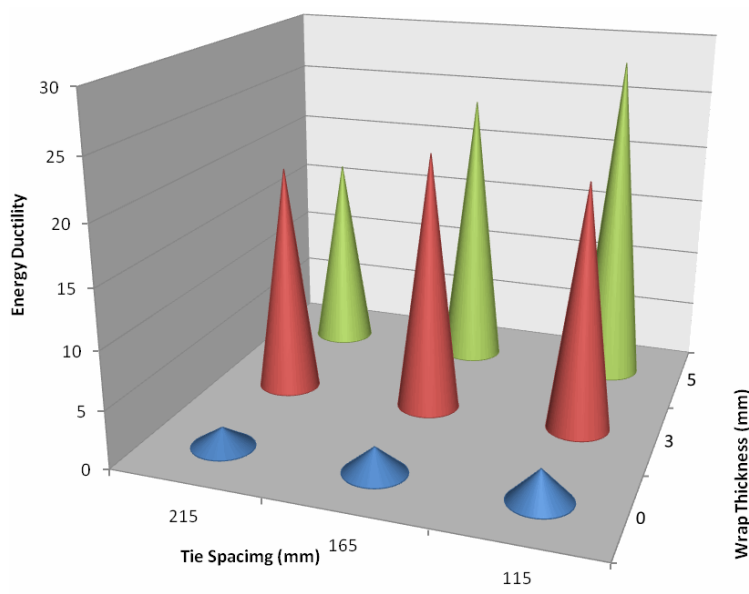

Fig. 4h: Energy ductility

indicative of the fact that the ductility of the wrapped columns also increased significantly, since the yield deflection levels of all wrapped and unwrapped columns were almost identical.

The column T115UDC5 showed the highest increase in lateral deflection at $994.53 \%$, closely followed by T115UDC3, which exhibited $973.70 \%$ increase in lateral deflection.

Effect of tie spacing on yield level performance: Changing the tie spacing from $215-165 \mathrm{~mm}$ resulted in a maximum increase of $11.25 \%$ in yield load and changing the same from $215 \mathrm{~mm}$ to $115 \mathrm{~mm}$ resulted in a maximum increase of $42.50 \%$ in yield load for $3 \mathrm{~mm}$ thick UDCGFRP wrapped column.

Columns with more effective wrapping showed higher levels of increase in axial yield deflection. The increase was by up to 31.92 and $78.40 \%$ for $3 \mathrm{~mm}$ 
UDCGFRP wrapped columns with 165 and $215 \mathrm{~mm}$ tie spacing respectively. The yield deflections for unwrapped columns were almost unaffected by the variation in tie spacing. The columns with 215 and 165 $\mathrm{mm}$ tie spacing showed the same yield deflection while the column with $115 \mathrm{~mm}$ tie spacing showed a marginal increase by $6.57 \%$ over the other two.

The unwrapped specimens with steel ties spaced at 165 and $115 \mathrm{~mm}$ showed 12.99 and $37.23 \%$ increase in lateral yield deformation over the specimens with steel ties spaced at $215 \mathrm{~mm}$. The highest increase in lateral yield deflection by $86.86 \%$ was exhibited by $3 \mathrm{~mm}$ thick UDCGFRP wrapped concrete column.

Effect of tie spacing on ultimate level performance: The effect of tie spacing was higher for $3 \mathrm{~mm}$ thick wrapping than for $5 \mathrm{~mm}$ thick wrapping. This might be an indication that the columns with sparse tie spacing can attain nearly the same load carrying capacity as those with closer tie spacing when wrapped with higher thickness of GFRP.

The unwrapped columns exhibited 4.11 and $10.96 \%$ increase in ultimate compressive load for tie spacing at $165 \mathrm{~mm}$ and $115 \mathrm{~mm}$ over the column having tie spacing of $215 \mathrm{~mm}$.

Column with $3 \mathrm{~mm}$ thick UDCGFRP showed extremely high levels of increase in axial deflection capacity by up to $108.79 \%$ for tie spacing of $115 \mathrm{~mm}$, when compared to the column with tie spacing of 215 $\mathrm{mm}$ having the same wrap.

\section{REGRESSION EQUATION FOR COMPRESSIVE STRENGTH}

Multivariate Regression analysis was carried out for estimating ultimate compressive strength of reinforced concrete columns confined with FRP composites. The equation proposed in this study is based on the basic equation proposed by Mander et al. (1988) for estimating the compressive strength of plain concrete confined by steel tubes, but widely adopted by for concrete confined by FRP as well (including ACI 440.2R, 2002).

The presence of longitudinal steel reinforcement in FRP confined concrete is accommodated by adding a component for the contribution of longitudinal steel. The effect of variation in tie spacing is accommodated by adding a regression coefficient multiplied by the confining pressure exerted by the steel ties per unit height of the column. The equation with unknown regression coefficients is:

$$
\begin{aligned}
\mathrm{f}_{\mathrm{rc}}= & \mathrm{a}_{0}+\mathrm{a}_{1} \mathrm{f}_{\mathrm{co}}^{\prime}\left[2.25 \sqrt{1+7.9 \frac{\mathrm{f}_{1}}{\mathrm{f}_{\mathrm{co}}^{\prime}}}-2 \frac{\mathrm{f}_{1}}{\mathrm{f}_{\mathrm{co}}^{\prime}}-1.25\right] \\
& +\mathrm{a} 2 \frac{\mathrm{f}_{\mathrm{yt}} \mathrm{A}_{\mathrm{t}}}{\mathrm{S}_{\mathrm{t}} \mathrm{A}_{\mathrm{g}}}+\frac{\mathrm{f}_{\mathrm{y}} \mathrm{A}_{\mathrm{st}}}{\mathrm{A}_{\mathrm{g}}}
\end{aligned}
$$

Where, the confining pressure $f_{l}$ may be estimated using the equation,

$$
\mathrm{f}_{1}=\frac{2 \mathrm{nt} \varepsilon_{\mathrm{fe}} \mathrm{E}_{\mathrm{f}}}{\mathrm{D}}
$$

The unknown coefficients $\mathrm{a}_{0}, \mathrm{a}_{1}$ and $\mathrm{a}_{2}$ are to be evaluated using regression analysis. The regression analysis was carried out using the data presented in Table 6. The regression analysis was carried out by treating the strength contribution of longitudinal steel as a neutral component, which remained unmodified by the regression analysis. This was in keeping with the ACI 440.2R expression for compressive strength which treated the strength of steel as a separate component. The values of regression coefficients fitted using the Legendre's principle of least squared errors are shown in Table 7. Incorporation of the numerical values of the regression coefficients leads to the equation,

$$
\begin{aligned}
\mathrm{f}_{\mathrm{rc}}= & \mathrm{f}_{\mathrm{co}}^{\prime}\left[2.95 \sqrt{1+7.9 \frac{\mathrm{f}_{1}}{\mathrm{f}_{\mathrm{co}}^{\prime}}}-2.62 \frac{\mathrm{f}_{1}}{\mathrm{f}_{\mathrm{co}}^{\prime}}-1.64\right] \\
& +37.65 \frac{\mathrm{f}_{\mathrm{yt}} \mathrm{A}_{\mathrm{t}}}{\mathrm{S}_{\mathrm{t}} \mathrm{A}_{\mathrm{g}}}+\frac{\mathrm{f}_{\mathrm{y}} \mathrm{A}_{\mathrm{st}}}{\mathrm{A}_{\mathrm{g}}}-18.37
\end{aligned}
$$

Table 6: Data for regression analysis

\begin{tabular}{llll}
\hline $\begin{array}{l}\text { Column } \\
\text { designation }\end{array}$ & $\begin{array}{l}\text { Strength of concrete } \\
\text { from Mander } \text { et al. } \\
(1988) \text { model }\end{array}$ & $\begin{array}{l}\text { Tie spacing } \\
\text { component } \\
\text { (MPa) }\end{array}$ & $\begin{array}{l}\text { Experimental } \\
\text { compressive } \\
\text { strength (MPa) }\end{array}$ \\
\hline T115R0 & 23.24 & 0.409773 & 15.84 \\
T165R0 & 23.24 & 0.285599 & 14.42 \\
T215R0 & 23.24 & 0.219181 & 13.57 \\
T115UDC3 & 39.37 & 0.409773 & 48.94 \\
T165UDC3 & 39.37 & 0.285599 & 41.87 \\
T215UDC3 & 39.37 & 0.219181 & 35.92 \\
T115UDC5 & 49.86 & 0.409773 & 51.77 \\
T165UDC5 & 49.86 & 0.285599 & 48.66 \\
T215UDC5 & 49.86 & 0.219181 & 44.98 \\
\hline
\end{tabular}

Table 7: Regression coefficients

\begin{tabular}{ll}
\hline Coefficient & Value \\
\hline $\mathrm{a}_{0}$ & -18.3694 \\
$\mathrm{a}_{1}$ & 1.3092 \\
$\mathrm{a}_{2}$ & 37.6463 \\
\hline
\end{tabular}




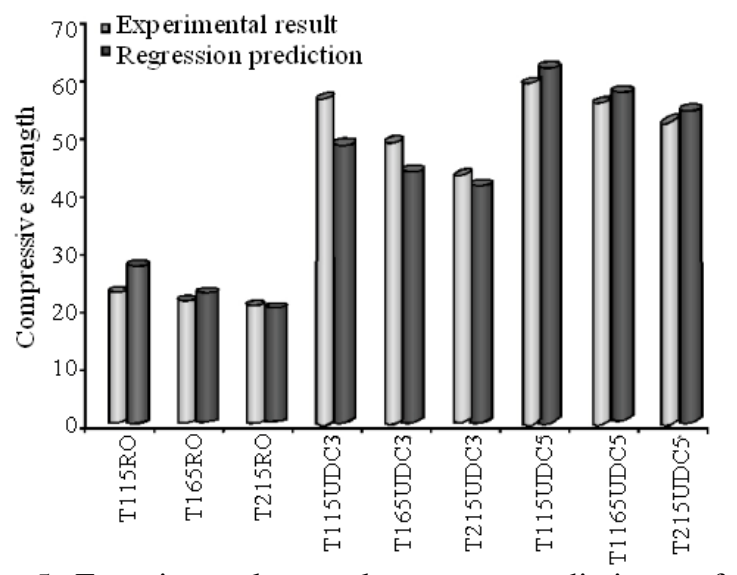

Fig. 5: Experimental results vs. predictions for compressive strength

The above equation predicted the compressive strength of reinforced concrete columns with Root Mean Squared Error (RMSE) of 3.81, Root Mean Squared Percentage Error (RMSPE) of $10.86 \%$, with fitness value of 0.936 . The predictions obtained from equation 2 were in good agreement with experimental results, as shown in Fig. 5.

\section{CONCLUSIONS}

The experimental investigations revealed that FRP confined reinforced concrete columns performed well at both yield level and ultimate level. The experimental results revealed that the spacing of internal steel ties and thickness of FRP wrap influenced the properties of the FRP confined reinforced concrete columns to a considerable extent. Following conclusions may be drawn from the experimental results:

- The compressive strength of FRP confined concrete column increased by a maximum of $159.21 \%$ for $5 \mathrm{~mm}$ thick UDCGFRP wrapped column.

- Decreasing the tie spacing from $215 \mathrm{~mm}$ to 115 $\mathrm{mm}$ resulted in $10.96 \%$ increase in the compressive strength of unwrapped reinforced concrete columns, indicating that changing the tie spacing influenced the strength of reinforced concrete column.

- The axial deflection of $3 \mathrm{~mm}$ thick UDCGFRP wrapped columns increased by $108.79 \%$ for tie spacing of 115 when compared to the column with $215 \mathrm{~mm}$ tie spacing.

- The regression equation proposed from the experimental data can estimate the compressive strength of reinforced concrete column with tie spacing as a parameter.

- The predictions of the regression equation agreed well with the experimental results. The fitness was 0.936 and the Root Mean Squared Percentage Error (RMSPE) was $10.86 \%$.

\section{ABBREVIATIONS AND NOTATIONS}

$\mathrm{A}_{\mathrm{g}}$

$\mathrm{A}_{\mathrm{st}}$

$\mathrm{A}_{\mathrm{t}}$

$\mathrm{D}$

$\mathrm{E}_{\mathrm{f}}$

$\mathrm{f}_{\text {co }}$

$f_{1}$
$f_{r c}$

$\mathrm{f}_{\mathrm{y}}$

$\mathrm{f}_{\mathrm{yt}}$

n

$\mathrm{RC}$

$\mathrm{S}_{\mathrm{t}}$

$=$ Thickness of each layer of FRP wrap

Reinforced Polymer

$\varepsilon_{\mathrm{fe}} \quad=$ Effective ultimate strain in FRP wrap at failure

\section{REFERENCES}

1. Becque, J., A.K. Patnaik and S.H. Rizkalla, 2003. Analytical models for concrete confined with frp tubes. ASCE J. Compos. Constr., 7: 31-38.

2. Deniaud, C. and K.W. Neale, 2005. An assessment of constitutive models for concrete columns confined with fibre composite sheets. Elsevier J Compos. Struct., 73: 318-330.

3. Hadi, M.N.S., 2006. Comparative study of eccentrically loaded frp wrapped columns. Elsevier J. Compos. Struct., 74: 127-135.

4. Legeron, F. and P. Paulre, 2003. Uniaxial confinement model for normal and highstrength concrete columns. ASCE J. Struct. Eng., 129: 241-252.

5. Li, G., D. Maricherla, K. Singh, S.S. Pang and M. John, 2005. Effect of fiber orientation on the structural behavior of frp wrapped concrete cylinders. Elsevier J. Compos. Struct., 74: 475-483.

6. Mander, J.B., M.J.N. Piestly and R. Park, 1988. Theoretical stress-strain model for confined concrete. ASCE J. Struct. Eng., 114: 1804-1826.

7. Mukherjee, A., T.E. Boothby, C.E. Bakis, M.V. Joshi and S.R. Maitra, 2004. Mechanical behavior of fiber-reinforced polymer-wrapped concrete columns-complicating effects. ASCE J. Compos. Constr., 8: 97-103.

8. Ozbakkaloglu, T. and M. Saatcioglu, 2007. Seismic performance of square high-strength concrete columns in FRP stay-in-place formwork. ASCE J. Struct. Eng., 133: 44-56. 